\title{
Evaluation of water resources management strategies to cover the shortage in future demands using the WEAP model in high Andean areas
}

\author{
Oscar Camarena-Campos ${ }^{1}$, Samuel Meza-Calderon ${ }^{1}$, Ada Arancibia, $\mathrm{PhD}^{1}$, and Sissi Santos, $\mathrm{MSc}^{1}$ \\ ${ }^{1}$ Ingeniería Civil, Universidad Peruana de Ciencias Aplicadas, Perú, \\ u201522133@upc.edu.pe,u20161b259@upc.edu.pe,pcciadar@upc.edu.pe, pccissan@upc.edu.pe
}

\begin{abstract}
Settlements in the Peruvian Andean highlands strongly depend on rainfed irrigation for agriculture activities and water supply depends on water storage capacity. This work analyses this vulnerable situation, for present and for future water demands and their coverage in the time horizon of 15 (2034) and 30 years (2049). For that, an application using WEAP software was carried on the "Blanco" watershed. Water resources were considered separately for each of the districts in the watershed, rather than analyzing together as a whole. The water-saving potential, the coverage of the demands for normal periods and dry periods, in addition to the different structural and non-structural measures, were analyzed under different simulated scenarios. The results show that different demands will increase considerably in all districts and that there will be a supply deficit after 2034 if there is no work on new water supplies. The decrease in water supply will occur from June to August. The installation of new reservoirs (structural measures), and better water distribution (non-structural measures) can generate water-saving potentials of $89 \%$ and $35 \%$ by 2034 , respectively, while the adoption of both strategies can save $100 \%$. Similarly, for 2049, the structural measures allow a saving of 50\% and the non-structural measures allow a saving of 35\%, while the use of both at the same time reaches $100 \%$.
\end{abstract}

Keywords-WEAP scenarios, evaluation, planning, water, shortage, water resources management

\section{INTRODUCTION}

Water is one of the most precious and indispensable resources for the life of man, animals, and plants. Being a scarce resource, it is an essential part of a country's wealth. In the world, around 2,100 million people do not have safe access to water, including having sanitary facilities in their homes [1]. Although access to water is a right, the fact that very few can have access, makes it a privilege, especially in rural areas of different countries globally.

This situation, although it is trying to be addressed by local governments, often with the help of international organizations, still does not seem to find satisfactory answers. Situation that becomes critical, because according to current statistics, there is an increase in the world's population that is on the rise, becoming one of the most considerable global risks, since it will increase the future demand for water resources. While most of the population (55\%) concentrates in urban areas (4.2 billion), about 3.4 billion people are living in rural areas worldwide, and the trend is expected to grow slightly over time [2].

In Peru, the rural population has not been indifferent to the global trend, such that, in 1993, the rural population was $6,589,757$ and by 2017 the rural population rose at $23 \%$ that is

Digital Object Identifier (DOI):

http://dx.doi.org/10.18687/LACCEI2020.1.1.574

ISBN: 978-958-52071-4-1 ISSN: 2414-6390
$7,344,000$ inhabitants which, the vast majority live in high Andean [3].

On the other hand, worldwide food production uses $69 \%$ of the total global extraction of water resources, while the Americas continent uses more than $50 \%$. Also, the projections of the percentage of water extraction are not encouraging, considering that currently 800 million people are hungry, it would be necessary to increase the percentage of resource extraction by $50 \%$ in the future to cover food demand [4].

In Peru, a country whose agricultural activities represent $5.3 \%$ of GDP and that these activities occupy $30 \%$ of the national territory, a good number of inhabitants are engaged in agriculture, approximately more than 2 million inhabitants. In the high Andean, there are 1.4 million inhabitants who live from agricultural activity, this is $64 \%$ of the total farmers in Peru [5]. Besides, rainfed agriculture is a general practice in these high Andean; consequently, they are vulnerable to lack of rainfall.

Therefore, it is essential to generate effective strategies for water resources management and thus cope with the probable shortage that is coming due to the growing demand and the unstable water supply. Condition generated due to various factors such as pollution of sources, the change in rainfall patterns, climate change, melting of glaciers, among others. Understanding that Water resources management implies administering, assigning, and efficiently controlling the use of water resources for its sustainability over time, not neglecting social, economic, and environmental objectives. Due to the complexity of this task, water resources managers require supporting tools to perform these analyzes. Among the various tools available are water resources management models, which allow simulating existing water offers and demands, to compare them with future demands, and thus be able to analyze whether the selected strategies for water resources management are the most appropriate. Currently, there are several water resources management models used in various investigations such as: QUAL2K, MODSIM, WEAP, MODFLOW, AQUATOOL, RIBASIM and WARGI-SIM; being the WEAP21 model, support for different researches in recent years on the management of water resources worldwide. This tool integrates the hydrological processes in the basin with the water resources management system, can directly receive climate, supply, and demand information. In addition, it allows for creating simulations in different scenarios.

\section{LITERATURE REVIEW}

From the literature review carried out, most of the works report the versatility of the WEAP model, showing various uses

18th LACCEI International Multi-Conference for Engineering, Education, and Technology: "Engineering, Integration, and Alliances for a Sustainable Development" "Hemispheric Cooperation for Competitiveness and Prosperity on a Knowledge-Based Economy", July 27-31, 2020, Virtual Edition. 
and applications; in this context, the following cases stand out. In the Sacramento-California basin simulation of runoff, interactions between groundwater and surface water, consumptive uses of agriculture and urban water, getting a Pearson's correlation coefficient between 0.82 and 0.94 in the calibration and testing. Those values demonstrate that WEAP can reproduce local and regional water balances, including managed and unmanaged flow, reservoir storage, agricultural and urban uses of water, and the allocation of underground and surface water supplies, being useful for various water planning processes [6]. Analysis of the impact of different socioeconomic development and climate change scenarios in Benin until 2025 with WEAP allowed planners to figure out the relevance of storage structure. Results indicate the necessity of improvements were more necessary in rural areas due to the decrease in water resources and increasingly deficient recharges due to climate change. This study identified that many stores in the area will dry out and that reservoirs could help mitigate the effects of scarcity. Also, it determines that groundwater potentially cope demands, but there is a limitation on the economic factor of Africa to implement the infrastructure and technology required [7]. WEAP applications include simulation of flow variation due to glaciers melting. The model of the "Santa" river basin, in Perú, with WEAP, simulates flows variations related to glaciers, runoff, and groundwater. In this study, the glacier module calibration considers an initial percentage of glacier coverage equal to $73 \%$. The correlation between the simulated and observed data is good enough (Pearson's correlation coefficient is $\mathrm{R} 2=0.7$ with $\mathrm{p} \leq 0.01$ ). The calibration and validation criteria indexes, such: RMSE, Bias, and Ef for all sub-basins, got acceptable values. Seasonally, the model shows that the melting glacier contributes $30 \%$ of the current flow during the wet season (December, January, February) and $67 \%$ during the dry season. Just for the subbasins with ice area, more than $20 \%$ of the total area. For groundwater, seasonal importance varies according to the conditions of each sub-basin. If the average proportion of groundwater is considered, the accumulation in the total output is $32 \%$ during the wet season and $35 \%$ during the dry season [8]. On the other hand, the WEAP model was used to investigate the effect of temperature and precipitation on surface hydrology, water infrastructure performance and irrigation coverage in the Limari basin in Chile. The study determines an increase of rainfall by $30 \%$ to compensate for the water cycle losses due to a temperature increase of $5^{\circ} \mathrm{C}$. The projected impact of climate change over the next 30 years suggested reductions of approximately 5, 10 and $15 \%$ on average in the La Paloma, Cogoti and Recoleta reservoirs, respectively [9]. In British Columbia, the WEAP model in the Okanagan basin was used to analyze structural and nonstructural measurements. The analysis includes surface storage systems capability to meet the needs of municipal flows and continuous flows in the Peachland district during the normal and dry years, creating different scenarios until 2050, in addition to proposals such as reducing demand in the short term. The results showed for the years with the deficit, a coverage between $64 \%$ and $82 \%$ of the demands. In the same scenario of climate change projected to 2050 combined with a higher demand for water and the construction of reservoirs resulted in better coverage of the demands, even though six out of every nine years a water deficit would be experienced in the area. By 2050 on average, annual deficits last 50 to 168 days, with only $38 \%$ to $71 \%$ of municipal and agricultural demands satisfied [10]. In China, the WEAP model was used in the XinanjiangFuchunjiang reservoir waterfall, located in the Hangzhou-China region. The study analyses whether the re-operation of a dam is an effective strategy to reduce possible climate impacts and the accelerated socio-economic developments. Also, water stress scenarios were used for the period between 2011 and 2040, being compared with periods from 1971 to 2000. The impacts of the scenario were simulated with the WEAP model. In this research the yield of the deposit is measured with the scarcity index (SI) and the average annual energy production (MAEP). For the proposed scenarios, the new proposals on average reduce the SI with $84 \%$ and increase the MAEP with $6.4 \%$ [11].

On the other hand, the WEAP model was used to evaluate the demand and supply of water resources at present and compare it with six possible scenarios, projected in Syria until 2050. The different proposed scenarios configurated through climate change, industrial development, regional cooperation, and implementation of new techniques, in addition to watersaving devices. The analysis of those scenarios considers the current situation, climate change, the best available technology, advanced technology, and regional cooperation. Implementation of structural measures, as improvement of water supply conveyance and modern irrigation systems, in the model, gets a shortage reduction of approximately 50\%, despite the growth of the population and industry. The results of a forced scenario showed that in Syria, more than $600 \mathrm{hm} 3$ / year could be saved by collecting rainfall, and water scarcity would be around $1500 \mathrm{hm} 3$ in 2050 [12].

This article presents the results obtained from water resources management to cover all water demands in a Peruvian Andean watershed. The implementation of management strategies that include structural and non-structural measures to meet the demands of water resources for dry periods in high Andean areas of Peru was formulated. Part of the watershed "Blanco" was chosen as a case study, for which a simulation model of water resources was built for the period 2019 to 2049 using the WEAP. This model includes subsystems for each district and detailed descriptions of the population and agricultural sectors. The potential water savings and water scarcity problems in different scenarios were analyzed, as well as the allocation of structural and non-structural measures. In addition to the water supply alternatives according to the scenarios, raw designs of the structural measures were presented. The results provide valuable information for the future planning of water resources and the formulation of district policies that are in the study area. This analysis can also provide some general ideas about urban and agricultural water savings. 


\section{CONTRIBUTION}

\section{A. WEAP Model Description}

The WEAP tool allows addressing a series of problems related to water resources, including the agricultural sector, both surface and underground water sources, demand analyses (domestic, agricultural and industrial), water management, water resource allocation according to priorities, reservoir operations including financial and cost management. Based on the linear programming structure, it solves the problems of water allocation in different time steps defined by the modeler [13]. Therefore, the conceptual model for this case would be as follows:

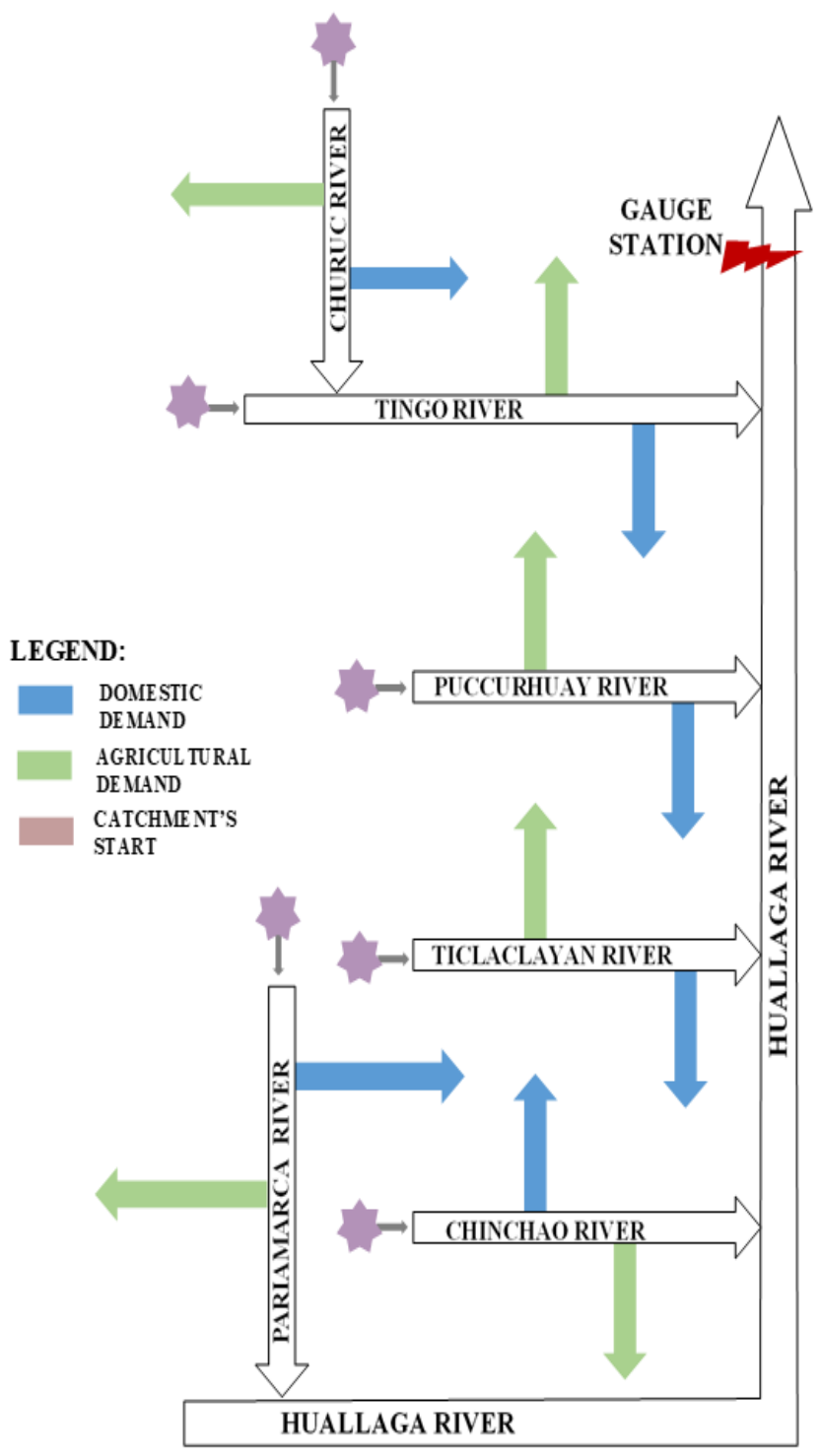

Figure 1. WEAP's conceptual model
The WEAP program has 5 ways to perform the water balance. For this research, the method of "Rainfall-Runoff" was used, for which we worked with (1):

$$
\begin{aligned}
R d_{j} \frac{d z_{1, j}}{d_{t}}=P_{e}(t) & -P E T(t) k_{c, j}(t)\left(\frac{5 z_{1, j}-2 z_{1, j}^{2}}{3}\right) \\
& -P_{e}(t) z_{1, j}^{R R F_{j}}-f_{j} k_{s, j} z_{1, j}^{2}-\left(1-f_{j}\right) k_{s, j} z_{1, j}^{2}
\end{aligned}
$$

Where:

- $z_{1, j}=[1,0]$ is the relative storage given as a fraction of the total effective storage in the root zone, $(\mathrm{mm})$ for land cover fraction.

- $R d_{j}(\mathrm{~mm})$. Effective storage capacity in the root zone for fraction $j$ of soil use coverage.

- $P_{e}$ : Effective precipitation including snow melting in the sub-catchment, calculated as $P_{e}=P_{i} m_{c}+m_{r}$, being:

- $m_{c}$ : melt coefficient defined as a function of melting and freezing temperatures.

- $m_{r}$ : melt rate calculated as $m_{r}=A c_{i} m_{c}$, where $A c_{i}$, is the snow accumulation calculated with the following expression:

$$
A c_{i}=A c_{i-1}+\left(1-m_{c}\right) P_{i}
$$

- PET. Potential evapotranspiration calculated according to Penman-Monteith, where $k_{c, j}$ is the crop coefficient for each fraction of soil cover.

- $P_{e}(t)\left(z_{1, j}\right)^{R R F_{j}}$ : This term represents surface runoff, where $R R F_{j}$ is the Runoff Resistance Factor of the soil cover. High values of this parameter imply less surface runoff.

- $f_{j} k_{s, j} z_{1, j}^{2}$. Represents the internal flow.

- $\left(1-f_{j}\right) k_{s, j} z_{1, j}^{2}$. It represents percolation.

- $k_{s, j}$. Root zone conductivity ( $\mathrm{mm} /$ time)

- $f_{j}$. Preferred flow direction. Partition coefficient related to the type of soil, cover and topography that divides the water horizontally and vertically.

\section{B. Methodology}

In the basin, high Andean areas with higher poverty rates and low agricultural production were identified, then a subbasin (watershed) was selected within the basin for a case study. Then the study area was characterized. Special attention was given to meteorological and hydrological data to determine water availability. Water demands were estimated according to peoples' economic activities and land use. After that, a supply-demand balance was made to obtain a diagnosis of the use of water resources in the area, using the WEAP model. At this point, the model was calibrated and validated to represent 
the current situation or baseline. Then, the needs and / or opportunities in the area were identified, which allowed formulating the Management Strategies that best fit the study area, these contemplated Structural, Non-Structural and Mixed measures. The Scenarios for analysis were defined, having as pillars the different projected demands, the needs and / or opportunities that arise in the area and the previously chosen measures. The results for each analyzed scenario were obtained using WEAP. The analysis included the evaluation water resources management strategies. Figure 2 shows the methodology followed.

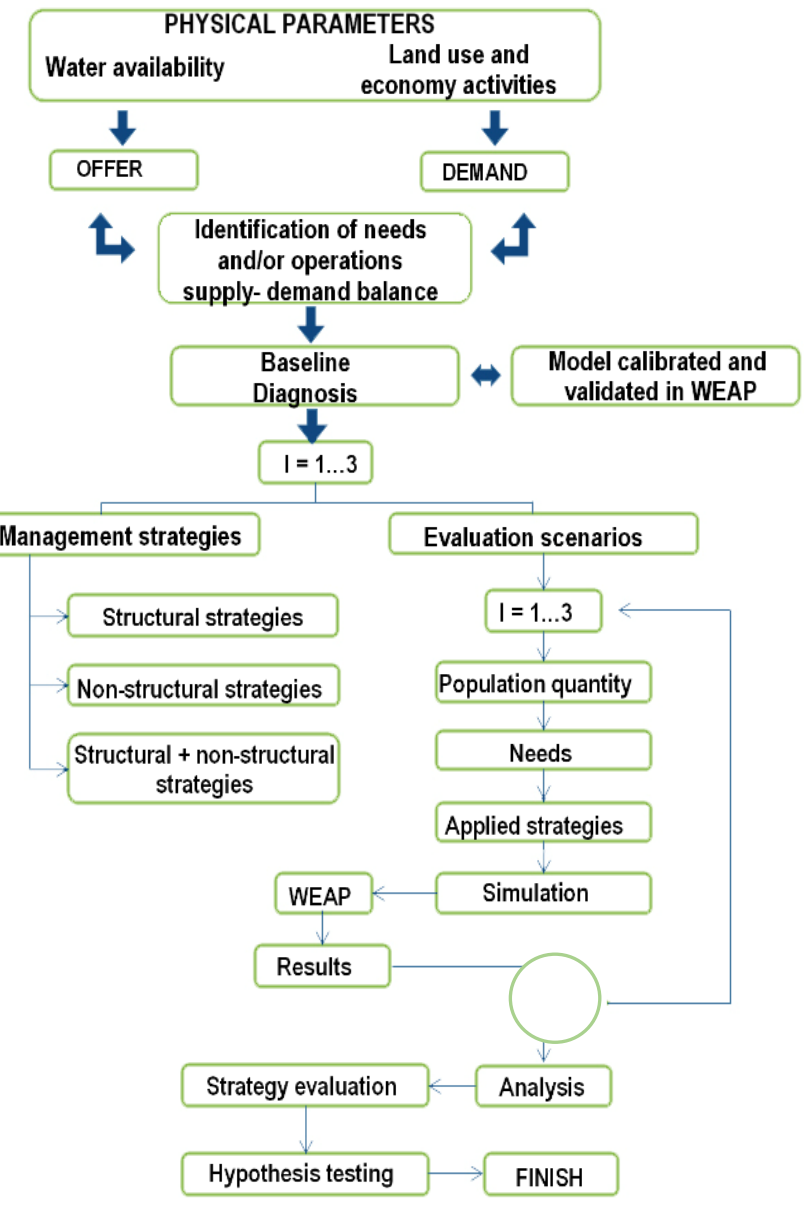

Fig 2. Methodology followed for this research

\section{Model Configuration}

The WEAP tool has been configured with Huallaga as its main river and as its tributaries the Tingo, Puccurhuay, Tulluracra, Chinchao, Ticlacayán and Pariamarca rivers (see figure 1). The "Blanco" watershed located upstream of San Rafael district was delimited. In total, 11 micro basins or catchments were delimited, considering the gauging and weather stations. The structure of the watershed "Blanco" is shown in figure 1, and subsequently, the demands (population and agricultural) were located, as shown in Figure 4.

In the calibration of the model for the period from 1983 to 1992, positive results were obtained in both the Nash-Sutcliffe index (0.71) and the Bias (-9.7\%). On the other hand, in the validation of the model for the period from 2003 to 2010, positive results were obtained for the Nash-Sutcliffe index $(0.83)$ and in the PBIAS $(-11.2 \%)$. In addition, Pearson's correlation coefficient was used to assess the goodness of the model fit, obtaining positive results in both calibration $(\mathrm{R}=$ $0.74)$ and validation $(\mathrm{R}=0.90)$.

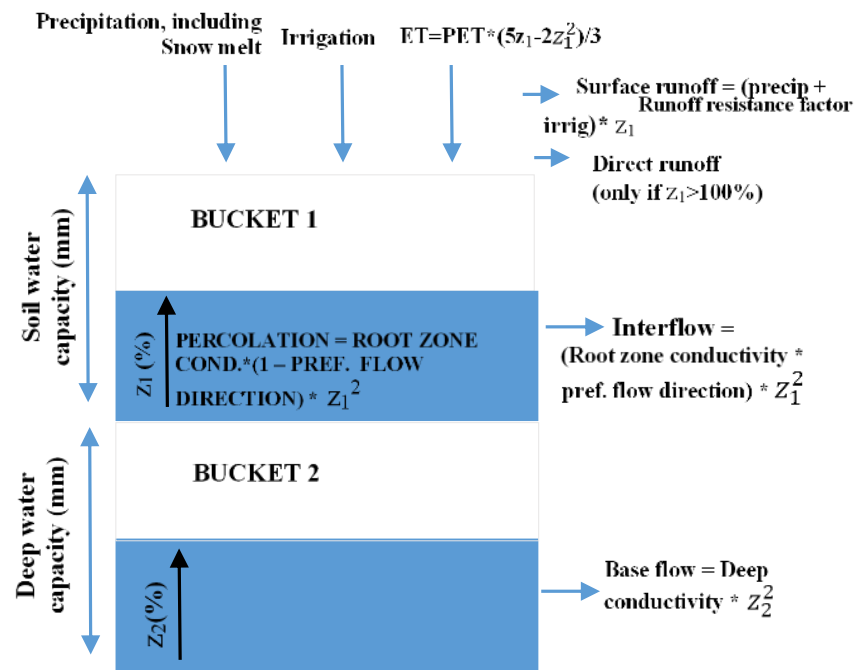

Fig 3. Conceptual diagram and equations incorporated in the Twobucket model [16]

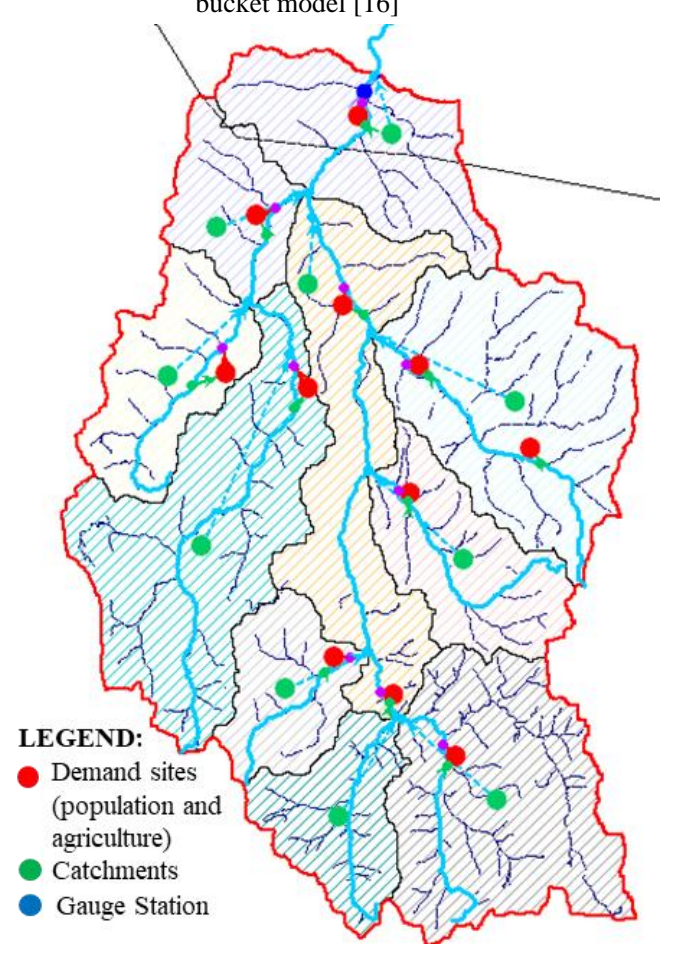

Fig 4. Location of catchments and demand sites 


\section{Case study}

\section{A. Study area}

"Blanco" watershed is $1565.5 \mathrm{~km}^{2}$, covers the departments of Huánuco and Pasco as shown in Figure 5 and is between latitudes $-10^{\circ} 21^{\prime} 03.5^{\prime \prime} \mathrm{W}$ and $-10^{\circ} 50^{\prime} 59.2^{\prime \prime} \mathrm{W}$ and the lengths -76 ${ }^{\circ} 22^{\prime} 12.1 " \mathrm{~S}$ and $-75^{\circ} 54^{\prime} 53.5^{\prime \prime} \mathrm{S}$. The study area includes nine districts.

This watershed is located at the head of the Huallaga River (a tributary of the Amazon River). The main tributary rivers are Tingo, Puccurhuay, Tulluracra, Chinchao, Ticlacayán, and Pariamarca. The altitude greatly influences the climatic variables, and this watershed is between 2500 and 5000 meters above sea level. In this area, the average annual temperature is $8^{\circ} \mathrm{C}$, the temperature in the summer months being between $15^{\circ} \mathrm{C}$ and $-8^{\circ} \mathrm{C}$, while in winter the temperature is between $11^{\circ} \mathrm{C}$ and $-2^{\circ} \mathrm{C}$. As for the average rainfall, it is around 1180 $\mathrm{mm} /$ year. In the months where there is little or no precipitation is between June and August. Wind speed is higher at higher altitude. Throughout the year the wind speed remains stable, although in June to September the maximum values are reached [14].

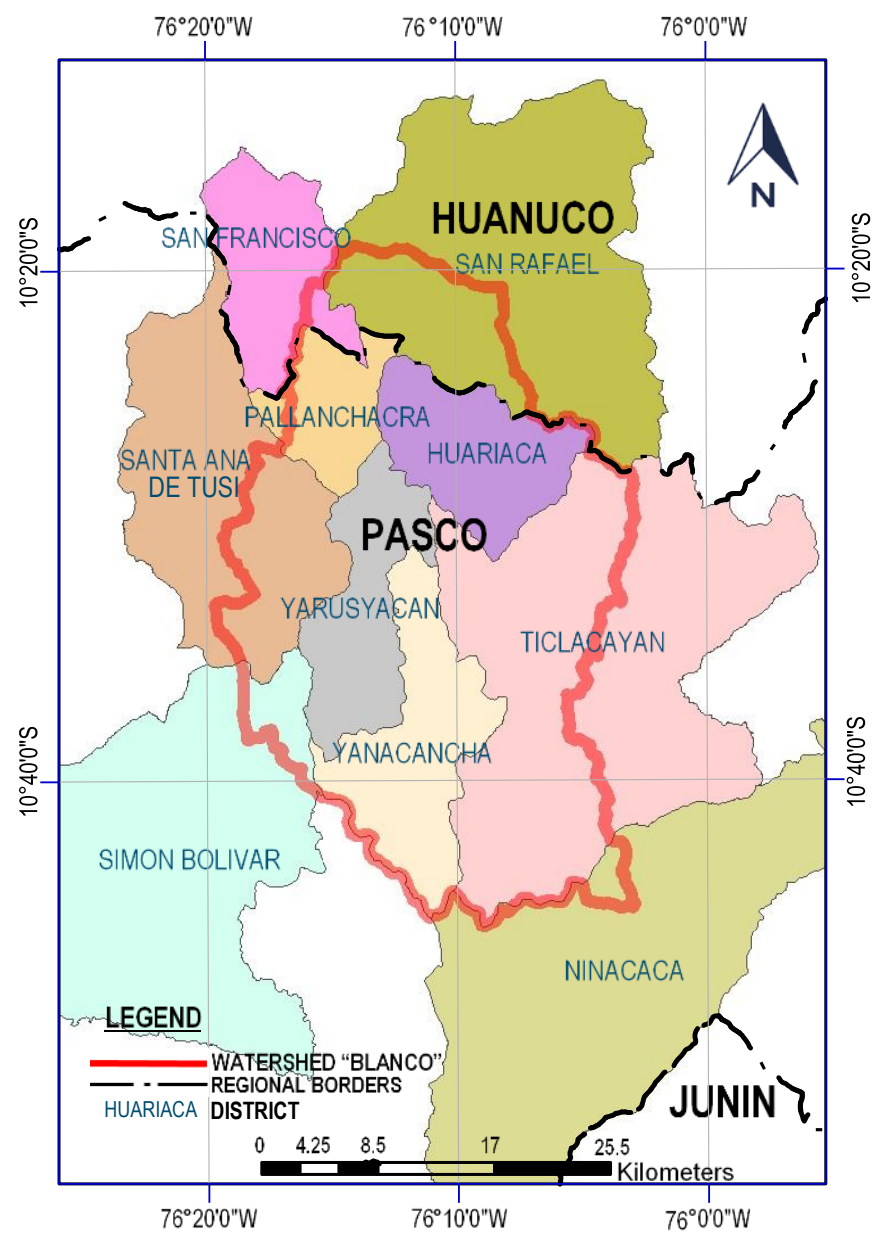

Fig 5. Study area location

\section{B. Physical and non-physical data}

In order to develop the model, data from different government institutions were requested and collected: Ministry of Health (MINSA), Ministry of Education (MINEDU), Ministry of Agriculture (MINAGRI), Ministry of Production (PRODUCE), National Water Authority (ANA), National Geographic Institute (IGN), National Institute of Statistics and Informatics (INEI), National Service of Meteorology and Hydrology of Peru (SENAMHI), Geological, Mining and Metallurgical Institute of Peru (INGEMMET), as well as data were collected on site making tours in the area. Table 1 shows the information and its source.

TABLE 1. DATA SOURCES

\begin{tabular}{|c|c|}
\hline Data & Source \\
\hline Cartographic & IGN \\
\hline Geological & INGEMMET \\
\hline Hydrological & ANA \\
\hline Meteorological & SENAMHI \\
\hline Socio - Economics & MINSA, MINEDU, INEI \\
\hline Population demand & INEI \\
\hline Agricultural demand & MINAGRI, PRODUCE \\
\hline Existing infrastructure & IN SITU \\
\hline Non-structural measures & MINAGRI, IN SITU \\
\hline
\end{tabular}

The hydro-meteorological data were selected between 1980 and 2010. The map of land use coverage was obtained from MINAGRI, the presence of the "Andean grassland" being predominant, as shown in Figure 6.

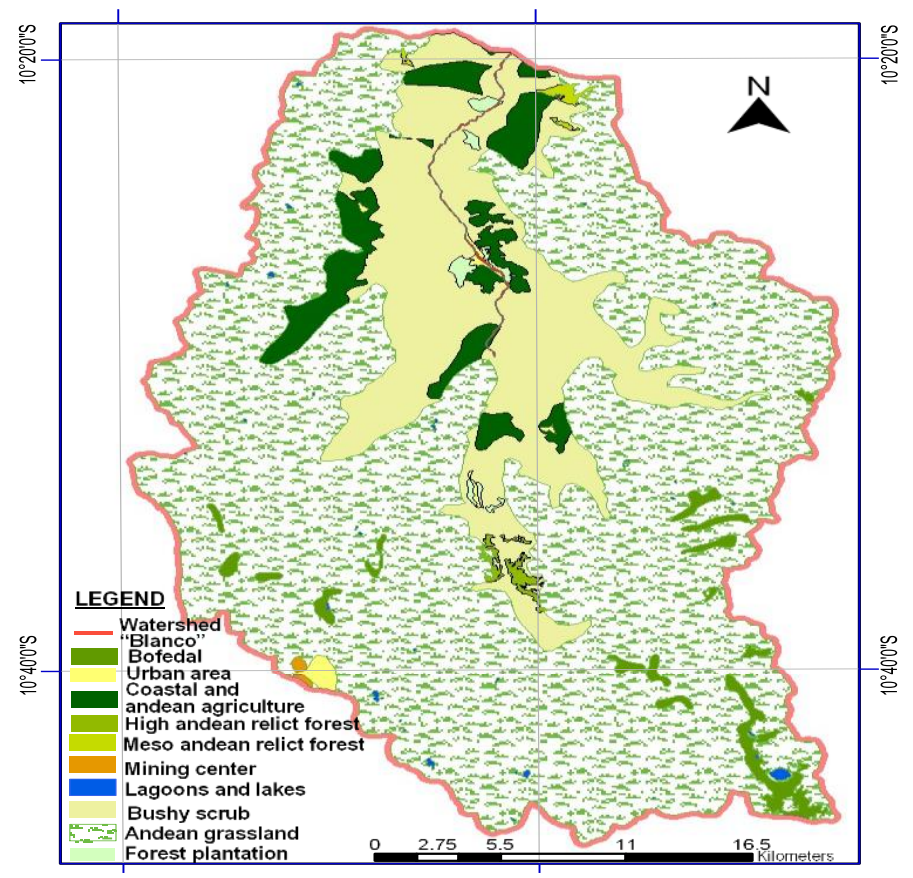

Fig 6. Study area land use coverage 


\section{Data treatment}

A serious difficulty in the high Andean areas is, on the one hand, the lack of hydro-meteorological stations, and on the other, the little maintenance given to existing ones. Such is the case, that there are gaps in both temperature records, as well as rainfalls. Therefore, data completion techniques were used. For this, a double-mass analysis was first performed. Then, the missing data was filled using the U.S. method National Weather Service (average with the inverse of the squared distance as a weighted factor; based on the percentage of participation that the missing data has on the monthly variable and for the linear regression).

\section{RESULTS}

The twelve possible scenarios formulated start from 2 types of conditions: "Normal Periods" (NP), and "Dry Periods" (DP). These periods were analyzed by implementing "structural measures" (SM), "non-structural measures" (NSM) and a "mix of both measures" (MX). They were running in two future scenarios 15 and 30 years.

The climatic conditions considered, following the FAO recommendations [17] and the worst scenario RCP 8.5, are:

- For the 15-year scenario in DP: $75 \%$ rainfall persistence and a temperature increase of $1^{\circ} \mathrm{C}$ is considered.

- For the 30-year scenario in NP, variations in precipitation of $+10 \%$ from January to March, $-10 \%$ in the remaining months and temperature increase of $1.5^{\circ} \mathrm{C}$. Based on this information the climatic conditions for the DP scenario were constructed.

\section{A. BU-Business as usual (no measures implemented) condition}

The following were considered:

1) Population growth.

Based on the growth rates from INEI [3], the values in Table 2 were considered.

TABLE 2. POPULATION GROWTH RATES

\begin{tabular}{|l|c|c|}
\cline { 2 - 3 } \multicolumn{1}{c|}{} & \multicolumn{2}{c|}{ Projection to } \\
\cline { 2 - 3 } \multicolumn{1}{c|}{} & $\mathbf{1 5}$ years & $\mathbf{3 0}$ years \\
\hline Growth rates & $18 \%$ & $39 \%$ \\
\hline
\end{tabular}

For the calculation of future population demand, the following formula was used.

Future Demand $=$ Current Demand $\times(1+\text { growth rate })^{\mathrm{N}^{\circ} \text { years }}$

\section{2) Agricultural demand growth}

For agricultural demand, it was estimated that of the total arable area, an additional $25 \%$ would be worked during some months of the year. For the calculation of arable areas, considering MINAGRI projections, the increase would be based on the annual increase of $15 \%$, as indicated in Table 3.
TABLE 3. AGRICULTURAL DEMAND GROWTH

\begin{tabular}{|l|c|c|c|c|}
\hline \multirow{2}{*}{ Growth } & \multicolumn{4}{|c|}{ Projection to } \\
\cline { 2 - 5 } & $\mathbf{1 5}$ years & \multicolumn{2}{|c|}{30 years } \\
\cline { 2 - 5 } & DP & NP & DP & NP \\
\hline Agricultural demand in area & $10 \%$ & $20 \%$ & $25 \%$ & $45 \%$ \\
\hline
\end{tabular}

Figure 7 shows the results of the run for years 2034 (15 years) and 2049 (30 years), under $\boldsymbol{B} \boldsymbol{U}$ conditions. It is observed that the demands are not covered from March to November, being more critical in the months of June to September, reaching the lowest value of $50 \%$ coverage for the month of August in the Dry Period scenario in 2049.

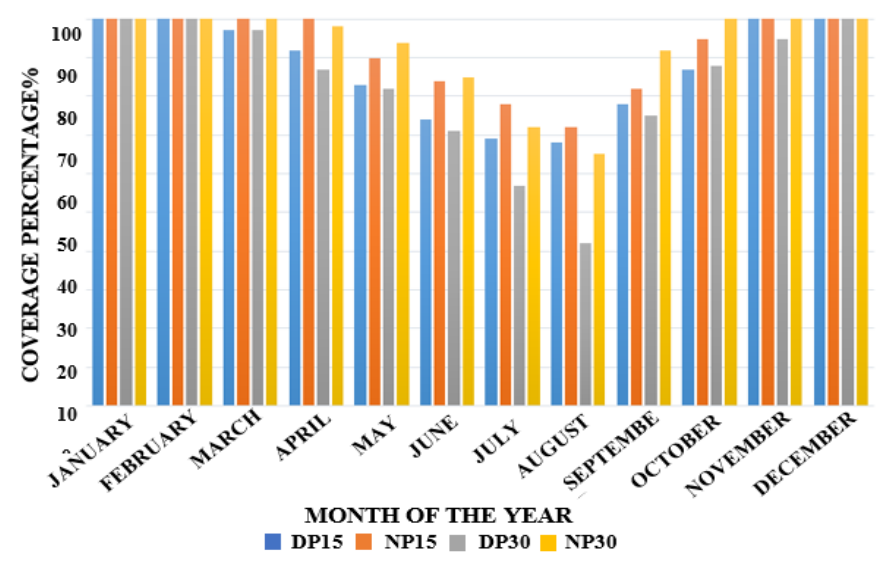

Figure 7. Total demand coverage in \% for BU conditions

A. Implementing water resources management strategies by 2034 (15 years)

1) Structural measures implemented

For normal periods, they were implemented to the drinking water supply and irrigation network in the WEAP model. At first, a $250 \mathrm{~m}^{3}$ capacity reservoir was proposed for each district capital, with not good results. Then $500 \mathrm{~m}^{3}$ capacity reservoir was proposed for each district capital. It also has double effluent conduction, one for the population and one for agriculture area; as shown in Figure 8.

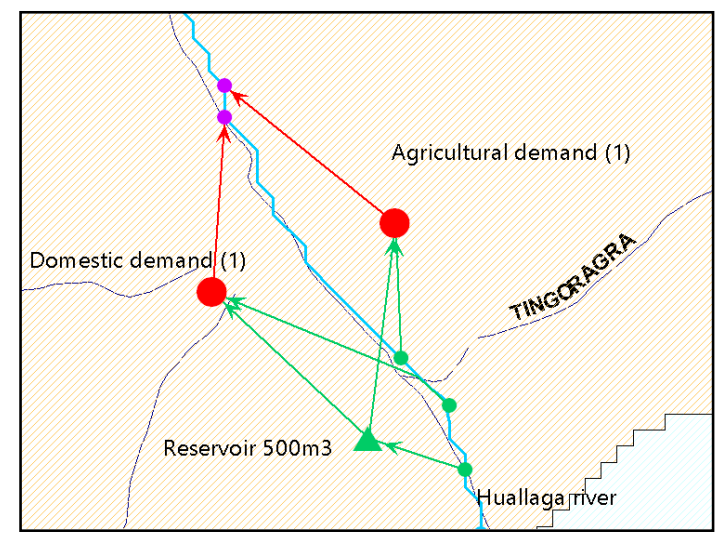

Fig 8. Proposed reservoir location in normal periods by 2034 
The $500 \mathrm{~m}^{3}$ capacity reservoir had positive effects in compensating part of the required flow; $0.07 \mathrm{~m}^{3} / \mathrm{s}$ for the population, while for agriculture area $1.02 \mathrm{~m}^{3} / \mathrm{s}$ on average.

For dry periods, a $1000 \mathrm{~m}^{3}$ capacity reservoir for each district was implemented in the drinking water supply and irrigation network. As a result, a percentage was obtained for the coverage of demands of at least $94 \%$.

\section{2) Non-structural measures implemented}

For normal periods, monthly training on saving techniques was proposed for farmers using sprinkler irrigation systems in $30 \%$ of their arable areas. In addition, monitoring of the unlined channels was proposed with monthly maintenance for sediment control.

For the dry periods, the installation of sprinkler and drip irrigation systems was handled in $75 \%$ of arable areas. In addition, people were trained monthly on how to improve water use when watering their crops.

3) Structural and non-structural measures implemented

For normal periods, the construction of a $500 \mathrm{~m}^{3}$ capacity reservoir and a water reuse program were proposed. To be applied simultaneously in the population as in agricultural areas. As a result, demand was met in all months except in August, which still has a deficit of $5 \%\left(0.61 \mathrm{~m}^{3} / \mathrm{s}\right)$. However, this situation would improve by increasing the capacity of the reservoir.

For dry periods, the volume of the reservoir was increased to $1500 \mathrm{~m}^{3}$. In addition, drip irrigation was installed, thus improving water use efficiency. In addition, mobile reservoirs (water tanks with a capacity of 600 liters) were installed for every 3 hectares. As a result, the demands were $100 \%$ covered. All the results obtained for the coverage of the demand in percentages, are summarized in table 4.

TABLE 4. COVERAGE OF TOTAL WATER DEMAND IN PERCENTAGE. IMPLEMENTED MANAGEMENT STRATEGIES FOR DRY AND NORMAL PERIODS

\begin{tabular}{|c|c|c|c|c|c|c|}
\hline \multirow{3}{*}{ Month } & \multicolumn{6}{|c|}{ 15 years (2034) } \\
\cline { 2 - 7 } & \multicolumn{3}{|c|}{ DP } & \multicolumn{3}{|c|}{ NP } \\
\cline { 2 - 7 } & $\begin{array}{c}\text { SM } \\
(\boldsymbol{\%})\end{array}$ & $\begin{array}{c}\text { NSM } \\
(\boldsymbol{\%})\end{array}$ & $\begin{array}{c}\text { MX } \\
(\boldsymbol{\%})\end{array}$ & $\begin{array}{c}\text { SM } \\
(\boldsymbol{\%})\end{array}$ & $\begin{array}{c}\text { NSM } \\
(\boldsymbol{\%})\end{array}$ & $\begin{array}{c}\text { MX } \\
(\boldsymbol{\%})\end{array}$ \\
\hline JAN & 100 & 100 & 100 & 100 & 100 & 100 \\
\hline FEB & 100 & 100 & 100 & 100 & 100 & 100 \\
\hline MAR & 100 & 100 & 100 & 100 & 100 & 100 \\
\hline APR & 100 & 98 & 100 & 100 & 100 & 100 \\
\hline MAY & 100 & 94 & 100 & 100 & 98 & 100 \\
\hline JUNE & 97 & 90 & 100 & 100 & 96 & 100 \\
\hline JULY & 90 & 80 & 100 & 100 & 90 & 100 \\
\hline AUG & 90 & 76 & 100 & 90 & 84 & 95 \\
\hline SEPT & 96 & 88 & 100 & 100 & 97 & 100 \\
\hline OCT & 100 & 100 & 100 & 100 & 100 & 100 \\
\hline NOV & 100 & 100 & 100 & 100 & 100 & 100 \\
\hline DEC & 100 & 100 & 100 & 100 & 100 & 100 \\
\hline
\end{tabular}

B. Implementing water resources management strategies by 2049 (30 years)

\section{1) Structural measures implemented}

For normal periods, a reservoir of $750 \mathrm{~m}^{3}$ capacity for each district capital and one of $150 \mathrm{~m}^{3}$ for each populated center in the influence area were implemented to the drinking water supply and irrigation network. Also, water intake systems were installed in some streams to feed the reservoirs of the populated centers, while the main reservoir feeds directly from the river upstream.

For the dry periods, a reservoir of $1000 \mathrm{~m} 3$ capacity for each district capital and one of $450 \mathrm{~m} 3$ for each populated center were implemented to the drinking water and irrigation supply network. In addition to guaranteeing the effluent quality, a wastewater treatment plant (WWTP) was designed to receive the return flow of the population demand in each micro basin. The locations of the reservoirs and their capacities are shown in figure 9 .

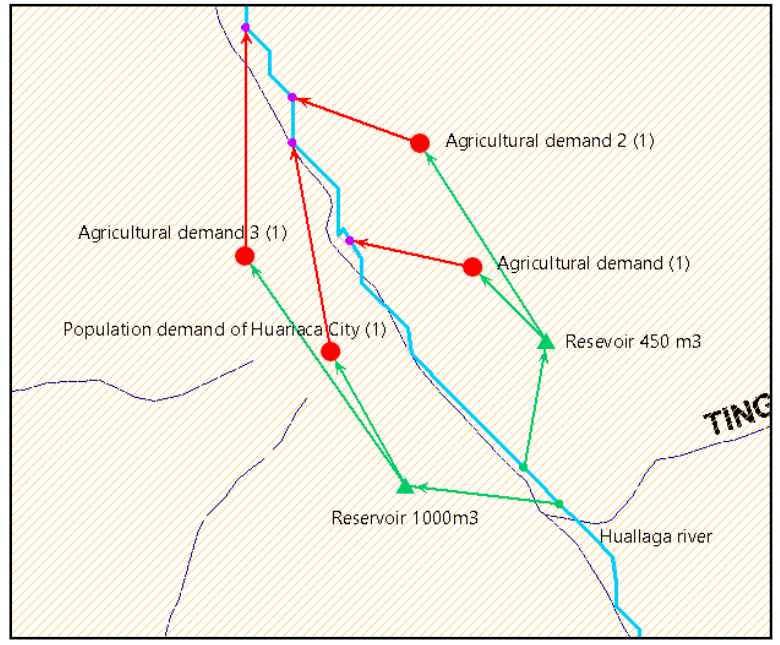

Fig 9. Reservoir locations in dry periods by 2049

\section{2) Non-structural measures implemented}

For normal periods, sprinkler and drip irrigation systems were implemented in 50\% of arable areas. In addition, the preventive maintenance of the unlined channels allowed to reduce the loss percentage to $50 \%$.

For dry periods, the installation of sprinkler and drip irrigation systems was proposed in 100\% of arable areas. In addition to the reuse of effluent from wastewater treatment plants.

3) Structural and non-structural measures implemented

For normal periods, reservoirs of $750 \mathrm{~m}^{3}$ were added for the cities and $150 \mathrm{~m}^{3}$ for the hamlets. In addition, sprinkler irrigation was used in 50\% of arable areas. On the other hand, the percentage of conduction losses was reduced as sleeves were used to transport the water resource

For dry periods, reservoir management, WWTP, sprinkler irrigation, water reuse were implemented. As a result, it was obtained that the coverage of the demands despite the climatic variations is $100 \%$ for all the months of the year. As a result, 
the demands were $100 \%$ covered. All the results obtained for the coverage of the demand in percentages are shown in table 5.

TABLE 5. COVERAGE OF TOTAL WATER DEMAND IN PERCENTAGE. IMPLEMENTED MANAGEMENT FOR DRY AND NORMAL PERIODS

\begin{tabular}{|c|c|c|c|c|c|c|}
\hline \multirow{3}{*}{ Month } & \multicolumn{6}{|c|}{30 years $(2049)$} \\
\hline & \multicolumn{3}{|c|}{$D P$} & \multicolumn{3}{|c|}{$N P$} \\
\hline & $\begin{array}{l}\text { SM } \\
(\%) \\
\end{array}$ & $\begin{array}{c}\text { NSM } \\
(\%) \\
\end{array}$ & $\begin{array}{l}\text { MX } \\
(\%) \\
\end{array}$ & $\begin{array}{l}\text { SM } \\
(\%) \\
\end{array}$ & $\begin{array}{c}\text { NSM } \\
(\%) \\
\end{array}$ & $\begin{array}{l}\text { MX } \\
(\%) \\
\end{array}$ \\
\hline JAN & 100 & 100 & 100 & 100 & 100 & 100 \\
\hline FEB & 100 & 100 & 100 & 100 & 100 & 100 \\
\hline MAR & 99 & 92 & 100 & 100 & 100 & 100 \\
\hline APR & 95 & 87 & 100 & 100 & 100 & 100 \\
\hline MAY & 89 & 77 & 100 & 95 & 87 & 100 \\
\hline JUNE & 84 & 73 & 100 & 90 & 83 & 100 \\
\hline JULY & 81 & 69 & 100 & 84 & 79 & 100 \\
\hline AUG & 86 & 65 & 100 & 82 & 75 & 100 \\
\hline SEPT & 93 & 78 & 100 & 94 & 86 & 100 \\
\hline OCT & 98 & 87 & 100 & 100 & 100 & 100 \\
\hline $\mathrm{NOV}$ & 100 & 97 & 100 & 100 & 100 & 100 \\
\hline DEC & 100 & 100 & 100 & 100 & 100 & 100 \\
\hline
\end{tabular}

\section{CONCLUSIONS}

It was determined that, with the current management conditions (business as usual) projected for the 2034 year, the supply covers the gross demand in almost every month of the year. Except for the period from March to November, with a deficit of up to $40 \%$ for the dry period. The projection for the year 2049 that considers more unfavorable climatic conditions (RCP8.5 scenario) [17], the deficit is of up to $60 \%$.

The implementation of strategies that at least include nonstructural measures (NSM) helps to improve coverage conditions of at least $65 \%$ for the most critical condition (dry period year 2049).

According to the results, from the strategies proposed, the structural measures (SM) are more effective than the nonstructural ones, with lower deficits for the dry period scenarios (11\% for 15 years and $19 \%$ for 30 years).

Only for the scenario where a combination of structural and non-structural measures (MX) is used can the water shortage in the entire watershed "Blanco" be resolved. However, some scenarios containing SM could partially solve water problems in some of the micro basins. The best solution was a combination of reservoirs with a capacity greater than or equal to $1000 \mathrm{~m}^{3}$ for each district capital, adding a monthly training.

WEAP software is a useful tool for water resources planning analysis of different strategies, as shown in this study.

It is concluded that the most effective strategy for this study is the implementation of mixed measures (structural and nonstructural measures).
The results obtained in this study will be useful for decision making and policy analysis for the development and management of water resources in the studied area.

\section{REFERENCES}

[1] United Nations Organization. (2018). Revision of World Urbanization Prospects. New York: UNDESA

[2] World Health Organization. (2017). 2.1 Billion people lack safe drinking wáter at home more tan twice as many lack safe sanitation. Ginebra: OMS Yates, D., Purkey, D., Sieber, J., Huber-Lee, A., Galbraith, H., West, J., . . . Rayej, M. (2009). Climate driven water resources model of the Sacramento Basin, California. Water Resour, 135,303-313.

[3] National Institute of Statistics and Informatics. (2017). Peru: population growth and distribution 2017. Obtained from https://www.inei.gob.pe/: https://www.inei.gob.pe/media/MenuRecursivo/publicaciones_digitales/E st/Lib1530/libro.pdf

[4] United Nations Food and Agriculture Organization. (2010). FAO. Obtained from http://www.fao.org/: http://www.fao.org/nr/water/aquastat/water_use/indexesp.stm

[5] Ministry of Environment. (2016). Peru and climate change. Obtained from the Third National Communication of Peru to the United Nations Framework Convention on Climate Change: http://www.minam.gob.pe/wp-content/uploads/2016/05/TerceraComunicaci\%C3\%B3n.pdf

[6] Höllermann, B., Giertz, S., \& Diekkrüger, B. (2010). Benin 2025Balancing Future Water Availability and Demand Using the WEAP "Water Evaluation and Planning' System. Water Resour", 24,3591-3613.

[7] Condom, T., Escobar, M., Purkey, D. et. al (2011) Modelling the hydrologic role of glaciers within a Water Evaluation and Planning System (WEAP): a case study in the Rio Santa watershed (Peru). Hydrology and Earth System Sciences, 8(1), 869-916. doi: https://doi.org/10.5194/hessd8-869-2011

[8] Vicuña, S., McPhee, J., \& Garreaud, R. (2012). Agriculture vulnerability to climate change in a snowmelt driven basin in semiarid Chile. J. Water Resour. Plan. Manag, 138,431-441.

[9] Harma, K., Johnson, M., \& Cohen, S. (2012). Future water supply and demand in the Okanagan basin, British columbia: A scenario-based analysis of multiple, interacting stressors. Water Resour, 26,667-689.

[10]Vonk, E., Xu, Y. Booij, M., Zhang, X. ,M. Augustijn, D. (2014). Adapting Multireservoir Operation to Shifting Patterns of Water Supply and Demand. Water Resources Management

[11]K., M., \& Alshihabib, O. (2014). Assessment of future Syrian water resources supply and demand by the WEAP model. Hydrological Sciences Journal, 393-401.

[12]Hernandez, E., \& Uddameri, V. (2015). Simulation-optimization model for water management in hydraulic fracturing operations. Hydrogeology Journal , 1247-1265.

[13]National Water Authority. (2015). Evaluation of Water Resources in the Huallaga Basin. Obtained from http://repositorio.ana.gob.pe/bitstream/handle/ANA/19/ANA0000049_1.p df? sequence $=1$

[14]Stockholm Environment Institute. (2019). WEAP . Obtained from https://www.weap21.org/: https://www.weap21.org/

[15]M. Young, The Technical Writer's Handbook, Mill Valley, CA: University Science, 1989.

[16]Stockholm Environment Institute. (2019). User Guide WEAP . Obtained from https:// https://www.weap21.org/downloads/WEAP_User_Guide.pdf

[17]Porfirio L.L.; Newth D.; Cai Y.; Finnigan J.J. (2017) Economic shifts in agricultural production and global trade from climate change - Technical Report. CSIRO Climate Science Centre; Oceans \& Atmosphere Business Unit, Australia. 